\title{
A MODERNIZAÇÃO TECNOLOGICA BRASILEIRA E O AJUSTAMENTO DOS RECURSOS HUMANOS
}

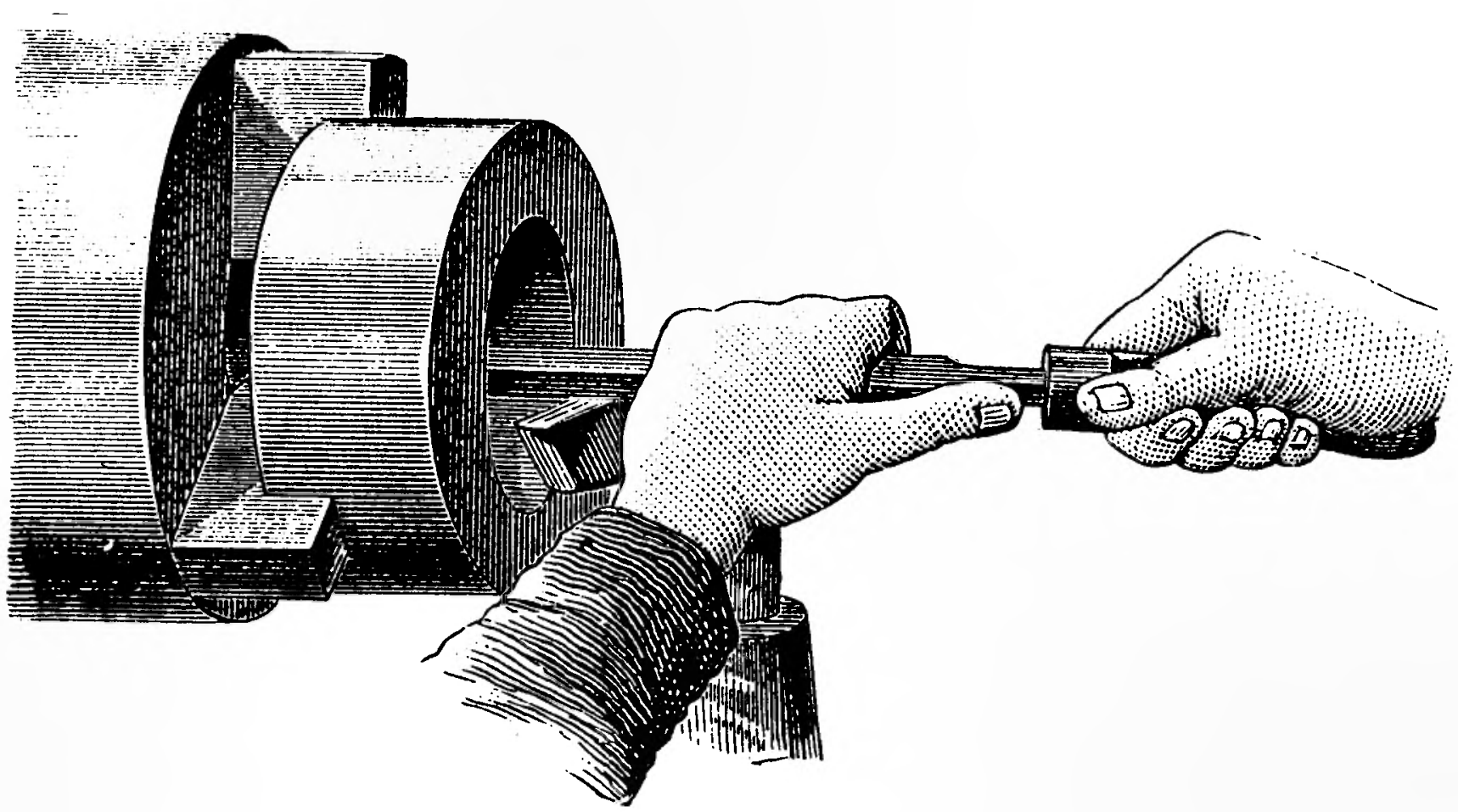

Anita Kon

Professora do Departamento de Planejamento e Análise Econômica da EAESP/FGV e da

FEA/PUC/SP, e doutora pela FEA/USP.

* RESUMO: O artigo examina os efeitos da modernização tecnologica sobre o ajustamento da Força de Trabalho, que é diferenciado para países com vários níveis de desenvolvimento. Enfoca a questão da escolha, pelos produtores, de técnicas apropriadas d̀s condições específicas de cada nação. Observa criticamente a situação brasileira $e$ as atuais condições para a busca da modernização tecnologica, enfatizando a necessidade do ajustamento da oferta de empregos à oferta de trabalhadores de cada espaço regional, que se apresenta diferenciada em termos de estruturas produtivas e distribuição ocupacional.
* PALAVRAS-CHAVE: modernização, tecnologia, recursos humanos, região, qualificação.

* ABSTRACT: The aim of this article is to investigate the impact of technological modernization upon Manpower adjustment, which is differentiated in countries with distinct levels of development. It focalizes the question of brazilian producer's choice with respect to the most appropriate techniques to fit nations specific conditions. It presents a critical appraisal of the brazilian situation, and it also examines the regional productive structures and domestic labor division.

* KEY TERMS: modernization, technology, human resources, regions, qualification. 


\section{INTRODUÇÃO}

A busca da modernização econômica envolve a determinação da sociedade brasileira de perseguir objetivos como reestruturação da competitividade interna e internacional das empresas, associada à elevação da capacidade de produção e da produtividade no sentido de baratear os custos e preços, via desenvolvimento tecnológico.

A tomada de decisão pelas empresas com respeito à alocação de investimentos voltados à modernização, por sua vez, está condicionada, entre outros determinantes, à disponibilidade relativa dos fatores de produção e dos níveis de produtividade associados à qualificação da mão-de-obra. Esta alocação tem como pano de fundo a escolha das novas tecnologias ou de novos produtos e está associada ao conhecimento das características qualitativas específicas da força de trabalho localizada no espaço potencialmente determinado como âmbito das inversões.

O caminho da modernização econômica passa sem dúvida pela introdução de processos de produção mais avançados, no sentido do aumento da produtividade e na escolha de tecnologias de ponta que permitam a competitividade no mercado internacional e a diminuição dos custos domésticos de produção. No entanto, o grau de introdução da inovação está sujeito à adequação da oferta de empregos às características peculiares da oferta de trabalhadores.

Visando a oferecer subsídios para a busca da modernização econômica do Brasil, este artigo tem a finalidade de examinar a distribuição ocupacional brasileira, observando suas características específicas, que se relacionam à composição da estrutura produtiva do país e ao grau de desenvolvimento tecnológico existente. Observam-se, no Brasil, diversidades regionais consideráveis nesses dois determinantes que, se num primeiro momento são condicionados pela natureza das forças de trabalho regionais, acabam posteriormente por condicionar a direção e o montante de investimentos voltados para a modernização econômica, concentrando-os nos pólos mais avançados, onde o retorno ao capital é mais rápido e seguro.

$\mathrm{O}$ exame aqui desenvolvido mostra que a realidade brasileira revela que alguns espaços nacionais não estão preparados, a curto prazo, para a absorção de tecnologias que demandem trabalho mais qualificado e, neste caminho, o desenvolvimento dos recursos humanos de modo a que se ajustem aos novos requisitos tecnológicos pode ter resultados em períodos mais longos. No entanto, as solu- ções criativas para o caminho da modernização econômica, em uma realidade como a do Brasil, além da busca de maior competitividade e produtividade, essenciais à retomada do desenvolvimento, implicam também na possibilidade de extensão da capacidade de absorção da força de trabalho a prazos menores, de forma efetiva e em condições satisfatórias, de modo a ampliar a renda global e o mercado interno. E, nesse sentido, a escolha da tecnologia, que atinja esses objetivos, nem sempre se volta para a tecnologia de ponta ou acentuadamente capital-intensiva, pois as características espaciais da mão-de-obra não permitem a introdução a curto prazo de técnicas que demandem níveis superiores de qualificação, sem a "importação" onerosa de recursos humanos ou o treinamento adicional a médio e longo prazos.

A análise aqui empreendida, que se inicia com algumas considerações teóricas sobre as implicações regionais da inovação tecnológica, tem por objetivo primeiramente o exame da situação do Brasil no cenário mundial, no que se refere à composição de sua distribuição ocupacional, tendo em vista as potencialidades do país na divisão internacional do trabalho na atualidade. Em seqüência, é efetuada uma observação das diversidades espaciais nas estruturas produtivas e nos níveis de qualificação da força de trabalho, como subsídio ao conhecimento da realidade interna do país, com vistas às possibilidades de introdução da modernização tecnológica, de forma diferenciada regionalmente.

\section{AS IMPLICAÇ̃̃ES REGIONAIS DA INOVAÇÃO TECNOLÓGICA}

É patente que a introdução da inovação tecnológica por parte de produtores públicos e privados implica em uma escolha entre diferentes possibilidades tecnológicas, que repercutirão na absorção de maior ou menor quantidade do fator trabalho, de diferentes niveis de qualificação, o que determinará a estruturação diferenciada das ocupações de forma adaptada aos processos produtivos escolhidos. As microunidades empresariais elegem sua tecnologia com vistas ao seu desenvolvimento econômico, levando em conta seus próprios objetivos de crescimento, os recursos de que dispõem, a natureza do mercado que operam, o conhecimento das opções tecnológicas disponíveis e a situação sócio-econômica em que estão operando, além dos subsídios governamentais oferecidos. No entanto, por outro lado, a escolha da tecnologia apropriada a essas condições, bem como o ritmo e a velocidade das inovações prendem-se tam- 
bém à capacidade de ajustamento da mão-deobra aos novos requisitos de qualificação advindos da introdução de técnicas inovadas.

De qualquer maneira, o desenvolvimento tecnológico implica em mudanças na capacidade produtiva das economias e na participação dos diferentes fatores de produção. Assim, esses conhecimentos técnicos atualizados possibilitam a formação de novos capitais, modificações na organização das empresas e na divisão de trabalho da sociedade.

Outras implicações dessas transformações referem-se à espacialidade deste progresso tecnológico e, observando-se os impactos internamente a cada espaço diferenciado de uma nação, essas mudanças são condicionadas pelo ritmo e velocidade em que se verificam os ajustamentos da força de trabalho ao processo de aceleração da especialização ou às formas mais atuais de organização da produção que objetivam a maior flexibilização da mão-de-obra para a execução de tarefas multi-especializadas e variadas. Estas condições estão associadas à tipicidade da estrutura ocupacional vigente naquele momento - ou seja, o perfil típico de sua distribuição ocupacional no que diz respeito à qualificação - e à capacidade da obtenção de maior qualificação a curto prazo pelos trabalhadores, o que irá repercutir na escolha da tecnologia a ser implantada em cada região, pelos produtores.

Paralelamente a essas implicações relacionadas à mão-de-obra, os processos de inovação tecnológica dependem da possibilidade de cada região ter condições de uma demanda potencial suficiente (interna ou externa) para o aumento da produção resultante, ou da capacidade daquela inovação induzir uma demanda pela nova produção. Por outro lado, estão sujeitos também à disponibilidade de poupanças internas ou externas à região, suficientes para financiar novos investimentos; isto por sua vez, implica na expectativa positiva de retornos vantajosos a estes investimentos de capital, que podem esbarrar nas condições de desvantagens relativas de determinados espaços econômicos. A par disto, é suposta uma dotação satisfatória de capital específica para investimentos públicos em infra-estrutura, que favoreça o processo de investimentos e de inovações naquele espaço.

Assim, é necessária uma combinação de capital privado e público e de uma oferta de mão-de-obra com qualificações específicas, como condição para a criação de mudanças tecnológicas consideráveis em uma região. Essas mudanças podem ser consideradas como fatores propulsores do processo de desenvolvimento econômico regional, e manifestam-se primordialmente por meio do fenôme- no de polarização sócio-econômica. $O$ espaço polarizado, ao propiciar vantagens na escala de produção, elos intersetoriais (linkages), disponibilidade de serviços complementares à produção e à distribuição de produtos, e dessa forma a possibilidade de maior grau de inovação tecnológica, molda as condições necessárias para uma rápida difusão dos impulsos de crescimento, dos setores propulsores para outros setores do mesmo espaço e posteriormente para outras regiões.

Historicamente, observou-se uma forte conexão entre atividades inovadoras e a dinâmica espacial, que se associam ainda à política de investimentos públicos em infra-estrutura, produzindo ciclos urbanos e regionais de desenvolvimento, paralelamente aos ciclos de inovação tecnológica, conforme constatou Nijkamp em suas pesquisas e foi observado empiricamente por Kon para o Brasil. ${ }^{1}$ Essa dinâmica faz-se sentir por meio de diferentes fases de desenvolvimento, que se relacionam aos centros urbanos mais avançados como núcleos-chave para a geração da inovação, e que condicionam e são condicionadas pelos movimentos de ajustamentos da mão-deobra.

Esses processos dinâmicos referem-se a efeitos de difusão geográfica da inovação tecnológica - que Myrdal descreve como efeitos de dispersão e de repercussão ("spread and backwash effects") $)^{2}$ - que se multiplicam via migração, fluxos de insumos e de produtos e fluxos de capital. Além do mais, quando as deseconomias de aglomeração ou os efeitos de congestão espacial se fazem sentir em determinadas áreas concentradoras do progresso tecnológico, as atividades inovadoras deslocam-se mais rapidamente para outras áreas. Assim, se o potencial inovador requer um patamar mínimo de dotação de infra-estrutura como fonte de desenvolvimento regional e/ou urbano, podem ocorrer efeitos de congestão, após um certo nível considerável de concentração.

Dessa forma, observamos a forte relação entre progresso tecnológico e a configuração espacial do desenvolvimento econômico, que implica em formas também diferenciadas de ajustamento da mão-de-obra a esta dinâmica, definindo distribuições diversas das estruturas ocupacionais regionalizadas.

Devemos aqui buscar a origem dessa dinâmica espacial, na evolução dos elementos resultantes de formas de organização da produção mais desenvolvidas, ou seja, na diminuição rápida dos custos de transportes, na redução do peso de alguns produtos industriais, no desenvolvimento do consumo em massa e na produção em grande escala, que
1. Veja-se NIJKAMP, P. "Technological Change, Policy Response and Spatial Dynamics". In: Evolving Geographical Structures, NATO, AST Series, Martinus Nijhoff Publishers, The Hague, 1983; KON, A. "A Segmentação Ocupacional do Mercado de Trabalho Brasileiro em uma Abordagem Regional". Estudos Econômicos, IPE/USP, nº Especial, 1989.

2. MYRDAL, G. Teoria Econômica e Regiōes Subdesenvolvidas. Ed. Saga, Rio de Janeiro, 1972. 
requerem uma estandartização dos processos mediante a extensa mecanização. Estes fatores permitem o emprego de trabalhadores não qualificados, bem como o recrutamento de nova força de trabalho em áreas carentes de tradições industriais, ao mesmo tempo que exigem maior qualificação de parcela da mão-de-obra.

Essas transformações não podem se materializar nas formas estruturais pré-existentes, pois requerem o apoio das grandes empresas e do Estado que, graças a seu poder técnico, financeiro e de organização, são capazes de implantar, em um contexto espacial, novos processos complicados de grande escala, ou ainda de menor escala, porém com modelos avançados tecnológicos e de gestão. $\mathrm{O}$ modelo de organização gerencial da grande empresa que implementa a divisão de suas operações através de departamentos especializados (por exemplo, direção, pesquisa, comercialização, produção, marketing etc.), permite que cada departamento busque a força de trabalho mais adequada, a um custo menor, muitas vezes propiciando a dispersão de sua produção por diferentes áreas, menos urbanizadas que os centros polarizados.

Essas diversidades espaciais nos níveis regionais de qualificação da força de trabalho repercutem na localização, pelos tomadores de decisões, da inovação tecnológica; nas áreas menos desenvolvidas, o baixo nível técnico dos processos produtivos escolhidos, por sua vez, traz consigo a ampliação do emprego menos qualificado, enquanto que nas outras áreas nota-se um crescimento mais rápido das qualificações e um grande desenvolvimento do emprego em ocupações de direção, pesquisa e administração, como observado a nível internacional por Schoenberger, Scott e Storper. ${ }^{3}$

Para o caso brasileiro, $\mathrm{Kon}^{4}$ observou que

3. SCHOENBERGER, E. "Multinational Corporations and The New International Division of Labor: A Critical Appraisal". International Science Review, 11(2), 1988; SCOTT, A.J. \& STOR$\mathrm{PER}, \mathrm{M}$. "Indústria de Alta Tecnologia e Desenvolvimento Regional: Uma Crítica e Reconstruçāo Teórica". Espaço e Débates, Cortez Ed. e Livr. Ltda., Ano VIII, $n^{0}$ 25,1988 .

4. Para detalhes empíricos consulte-se KON, A. "Consideraçōes sobre os Diferenciais Regionais da Estrutura Ocupacional Brasileira". Anais do XVIII Encontro Nacional de Economia, 3, ANPEC, Fortaleza, 1989. manos e de infra-estrutura de serviços complementares.

\section{O BRASIL NO CENÁRIO MUNDIAL}

Examinando-se a realidade brasileira, o que se observou historicamente para o país como um todo é que a modernização tecnológica e a conseqüente reestruturação da divisão do trabalho apresentaram uma dinâmica mais intensa a partir de meados da década de cinqüenta até os finais dos anos setenta (nesta última década, verificando-se em maior grau), quando foram relativamente mais elevadas as taxas anuais de crescimento da população envolvida em ocupações mais qualificadas técnicas, científicas e administrativas. Verifica-se que, neste período, a taxa média anual de crescimento dos investimentos esteve em torno de $11 \%$, o que no cenário mundial situava o país entre os mais dinâmicos.

No entanto, face ao período conjuntural crítico na economia do País, a década de oitenta revelou-se, relativamente aos períodos anteriores, uma época de queda nas taxas anuais de investimentos em Formação Bruta de Capital Fixo (-0,9\%, comportamento compatível com os países de Renda Média Baixa) que se não evitaram um maior sucateamento da indústria, não prosseguiram com o ritmo de modernização anterior, o que vem se repetindo nos primeiros anos da década de noventa. As políticas governamentais de estabilização postas em prática neste período atenuaram as transformações estruturais relevantes que decorriam do continuado processo de inovação tecnológica. Assim, o ajustamento do trabalho nestes últimos anos fez-se sentir primordialmente na diminuição do nível geral do emprego, nas realocações de trabalhadores de empresas para situações como Conta Própria e de assalariados que trabalhavam com carteira assinada para a condição de trabalho sem carteira, e não na continuação das transformações na estrutura ocupacional em direção à maior qualificação.

Como resultado, observou-se a interrupção do caminho da modernização e, no cenário mundial, o País retrocedeu relativamente a algumas nações que apresentavam o mesmo ritmo de desenvolvimento nas décadas anteriores, como por exemplo os países do Leste asiático, com os quais compunha, juntamente com a Argentina e o México o grupo dos NICs ("Newly Industrialising Countries" ou Países de Industrialização Recente). Após a Segunda Guerra até os finais da década de 1970, o capital transnacional impulsionou substancialmente essas economias em desenvolvimento, entre as quais se incluia o Brasil, 


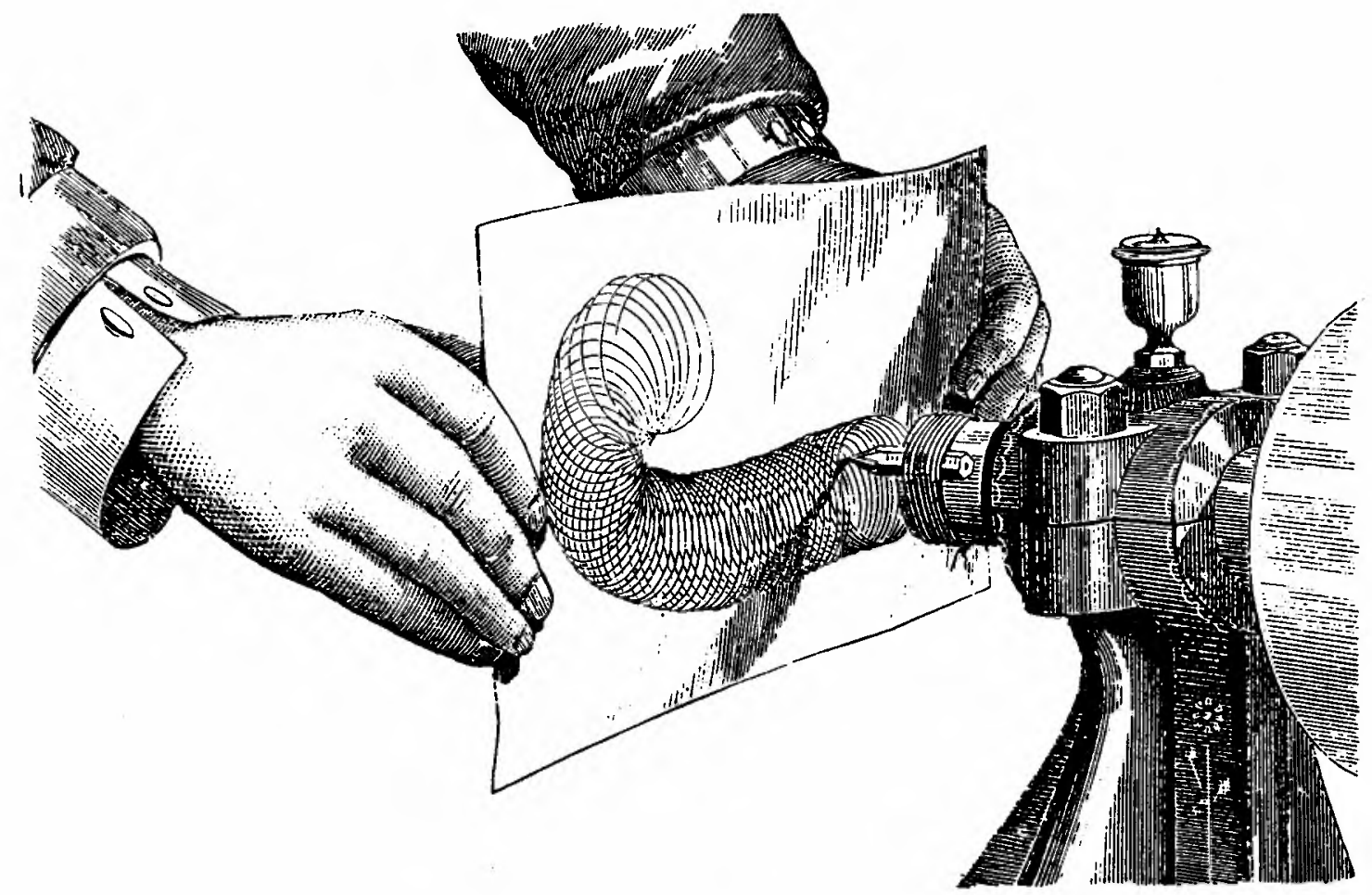

e buscava alocar-se em nações em que os custos relativamente menores da mão-de-obra tinham um poder de atração considerável, condicionando uma divisão internacional do trabalho baseada nas vantagens comparativas dos países com grande disponibilidade de trabalho menos remunerado. No entanto, a partir dos anos oitenta, as transformações tecnológicas baseadas em formas flexíveis de organização do trabalho e do processo de produção (experimentadas inicialmente no Japão e nos países do Leste europeu, mas que rapidamente estão se difundindo para os demais países avançados) resultaram numa nova tendência internacional que prioriza a demanda por trabalho mais qualificado, e a internacionalização do capital produtivo busca economias que se adaptem à possibilidade de oferecer mais rapidamente serviços complementares mais sofisticados. Nesse contexto, observa-se uma reorganização econômica e uma nova divisão mundial do trabalho, em que o Brasil apresenta desvantagens no que se refere à oferta de trabalho. O trabalho menos qualificado e mais barato deixa de apresentar vantagens comparativas em termos de custos de produção e distribuição de produtos.

Os padrões característicos da divisão de trabalho brasileira revelam a defasagem entre as condições atuais da composição da força de trabalho e as metas internas ou internacionais de modernização. O Brasil na atualidade situase entre países considerados pelo Banco Mundial como de Renda Média Alta em termos de $\mathrm{PNB} /$ capita, no entanto os níveis educacionais e a distribuição ocupacional o aproximam mais intensamente das nações de Renda Média Baixa, como é visualizado na tabela 1 .

De uma maneira global, as informações revelam que as configurações das estruturas ocupacionais dos países (representadas pela participação dos trabalhadores em grupos de ocupações definidos) resultam de duas condições básicas:

a) das características das respectivas estruturas produtivas e

b) dos níveis de desenvolvimento tecnológicos dos processos produtivos.

Os países de menor renda per capita baseiam 
sua economia substancialmente na produção rural e apresentam uma participação média de trabalhadores nessas ocupaçōes em torno de $57 \%$; a par da menor representatividade relativa de ocupados no setor Secundário, revelam ainda um baixo percentual de ocupaçōes mais qualificadas técnicas, científicas e administrativas, inferindo-se menor nível de avanço tecnológico nos processos produtivos. À medida do aumento dos níveis de desenvolvimento e de industrialização e terciarização observados nas estruturas produtivas dos países, as participações dos trabalhadores nessas ocupações mais qualificadas e na prestação de serviços aumentam, em detrimento da representatividade do
Setor Primário, até atingir um nível de maturação. Isto se verifica porque em vista das transformaçôes por que passam os processos produtivos das empresas com o desenvolvimento tecnológico é observada uma reestruturação das organizações administrativas com a finalidade de gerenciar-se um volume maior de operações e de assumirem-se tarefas técnicas e científicas especializadas, ao lado do desenvolvimento de serviços necessários para a satisfação de novos padrões de demanda, como financeiros, de consultoria, de manutenção e mesmo pessoais, que resultam em um processo de desindustrialização, ou seja, a força de trabalho se incorpora crescentemente nesse Se-

Tabela 1: Indicadores sócio-econômicos médios mundiais, segundo faixa de renda

\begin{tabular}{|c|c|c|c|c|c|}
\hline $\begin{array}{l}\text { Faixa de renda } \\
\text { Indicadores }\end{array}$ & $\begin{array}{l}\text { Baixa } \\
\text { Renda }\end{array}$ & $\begin{array}{l}\text { Renda } \\
\text { Média } \\
\text { Baixa }\end{array}$ & $\begin{array}{l}\text { Renda } \\
\text { Média } \\
\text { Alta }\end{array}$ & $\begin{array}{l}\text { Industria- } \\
\text { lizados }\end{array}$ & Brasil \\
\hline PNB/capita (US\$) & 290 & 1.200 & 2.710 & 14.430 & 2.020 \\
\hline Investimento/1980-87 (\%a.a.) & 1,8 & $-3,7$ & 0.1 & 3,1 & $-0,9$ \\
\hline \multicolumn{6}{|l|}{ Educação $(\%)^{*}$} \\
\hline Secunntária & 35 & 51 & 59 & 92 & 36 \\
\hline Superior & 1 & 17 & 20 & 39 & 11 \\
\hline \multicolumn{6}{|l|}{ Distribuição ocupacional (\%) } \\
\hline Técnicas e científicas & 3,0 & 6,2 & 10,1 & 17,7 & 6,7 \\
\hline Adm:nistrativas & 3,8 & 6,5 & 16.4 & 21,6 & 13,1 \\
\hline $\begin{array}{l}\text { Indústria, Transp., } \\
\text { Comunicacão }\end{array}$ & 19,0 & 20,3 & 30,7 & 32,0 & 23,2 \\
\hline Agropecuȧrias & 57,0 & 45,0 & 15,4 & 6,5 & 27,1 \\
\hline Comércio & 8,4 & 9,0 & 11,0 & 9,6 & 9,3 \\
\hline Serviços & 8,8 & 13,0 & 16,4 & 12,6 & 20,6 \\
\hline \multicolumn{6}{|l|}{ Estrutura produtiva (\% PIB) } \\
\hline Primário & 31,0 & 15,0 & 10,0 & 3,0 & 11,0 \\
\hline Secundário & 24,0 & 37,0 & 40,0 & 36,0 & 38,0 \\
\hline Terciário & 45,0 & 48,0 & 50,0 & 61,0 & 51,0 \\
\hline
\end{tabular}

FONTE: World Development Report/1989 e Year Book of Statistics/1989.

* Número de estudanles como percentual do grupo etário correspondente. 
tor Terciário complementar.

Para a média do Brasil, embora a estrutura produtiva ainda revele uma situação compatível à dos países de Renda Média Alta, no entanto, menos de $7 \%$ de pessoas ocupadas exercem atividades técnico-científicas qualificadas o que, em uma comparação internacional revela um padrão consideravelmente abaixo da média dos países desse nível de desenvolvimento que possuem em torno de $10 \%$ de pessoas nessas colocações. $\mathrm{O}$ mesmo se verifica com relação às ocupações administrativas e industriais que revelam uma representatividade inferior à maior parte dos demais países de Renda Média Alta.

Paralelamente, o baixo nível de representatividade de pessoas engajadas no ensino de Primeiro e Segundo Graus e Superior em relação a outras nações da respectiva faixa de renda explica este desajustamento, que se manifesta numa capacidade diminuída ou em menor velocidade de ajustamento da força de trabalho às necessidades de qualificação impostas pela modernização. Para o global do País, cerca de $47 \%$ dos ocupados exercem atividades semiqualificadas porém que exigem baixo nível de capacitação. Por outro lado, observa-se um percentual considerável de trabalhadores autônomos menos qualificados (cerca de $1 / 4$ da população ocupada) que, na sua grande maioria, assim se situam por não encontrarem condições satisfatórias de trabalho em empresas.

Para o agravamento das condições internas de modernização do Brasil, contribui o baixo nível de investimentos da década de 1980, face às políticas econômicas recessivas que objetivavam a estabilização. ${ }^{5}$ Se o crescimento populacional esteve em torno de $2,4 \%$ ao ano, os investimentos observaram uma queda anual de $0,9 \%$ até 1987 , o que resultou num recrudescimento do atraso tecnológico relativo do país no cenário mundial.

\section{AS DIFERENÇAS REGIONAIS NA ESTRUTURA PRODUTIVA BRASILEIRA}

A observação a nível regional, no entanto, revela dispersões consideráveis nestes padrões médios do país, como é notório. Estas diferenciações resultam da concentração historicamente inicial de investimentos em inovação tecnológica na região Sudeste, e a posterior difusão dessa modernização assumiu aspectos de "desconcentração concentrada" em torno desse centro polarizador. Isto se verificou face ao desenvolvimento de economias de aglomeração ocasionadas pela disponibilidade de infra-estrutura de serviços complementares por um lado, e da situação mais privilegiada de seus recursos humanos em ter- mos de qualificação e de condições de treinamento adicional, que acarretam às empresas maiores retornos na localização nessas áreas. ${ }^{6}$

As estruturas produtivas espaciais observadas refletem esta polarização, como é visualizado na tabela 2 , haja vista a forte concentração da população ocupada nas atividades industriais dinâmicas paulistas, particularmente na Indústria de Transformação (42\% dos trabalhadores do país dedicam-se a essas atividades). Como ocorre a âmbito mundial, também internamente ao País, a níveis diferenciados de renda per capita correspondem estruturas produtivas em diferentes estágios de transformações, que determinam "especializações" específicas em setores de atividades econômicas.

Salienta-se, inicialmente, que nas regiões em que se apresentam as maiores concentrações de trabalhadores, se observam os maiores contrastes em termos de desenvolvimento econômico, ou seja, no Nordeste alocam-se acima de $27 \%$ dos trabalhadores do país, contribuindo com cerca de $12 \%$ do PIB nacional e com uma renda per capita pouco acima de US\$ 750, enquanto que o estado de São Paulo ocupa $23 \%$ das pessoas, gerando acima de $39 \%$ do PIB brasileiro e com uma renda per capita próxima a US\$ 3.300. Portanto, apesar da concentração semelhante de trabalhadores nos dois espaços, as composições das estruturas produtivas são substancialmente diferentes.

Observando-se os Quoficientes de Especialização Regional (QEsj) para os diferentes setores, que refletem as "vocações" espaciais para as diferentes atividades, verificam-se índices superiores à unidade para a maior parte dos setores das regióes mais avançadas do Rio de Janeiro e de São Paulo, o que significa uma especialização regional com relação à média nacional. No entanto, o primeiro estado é mais especializado em atividades terciárias, enquanto que para São Paulo é mais considerável a especialização na Indústria de Transformação.

A região Sul, a que engloba os estados de Minas Gerais e Espírito Santo e a região do Centro-Oeste situam-se em um nível intermediário de desenvolvimento, com rendas per $\mathrm{ca}$ pita situadas entre US $\$ 1.500$ e 2.000 , porém as estruturas produtivas das duas primeiras mostram uma especialização mais intensa no setor Primário, enquanto que a da última reflete a influência da capital nacional, com maior concentração em atividades de serviços, particularmente da Administração Pública. Embora os QEsj do setor Secundário da região Sul do País se apresentem inferiores à unidade, revelando a não especialização nestas atividades, a absorção relativa de trabalhadores nas indústrias de Transformação e de Construção é ainda superior à do Rio de Janeiro, e equipa-
5. Uma discussão adicional é desenvolvida em KON, A. Padrões e Condicionantes da Estruturação Ocupacional Brasileira: uma abordagem inter-regional. Tese de Doutorado, FEAUSP, 1990 Capítulo 4.

6. Para maiores detalhes, consultar KON, A. Padrões Condicionantes da Estruturação Ocupacional Brasileira: uma abordagem inter-regional. Op. cit., Capítulo 7. 
Tabela 2: Distribuição regional das atividades econômicas

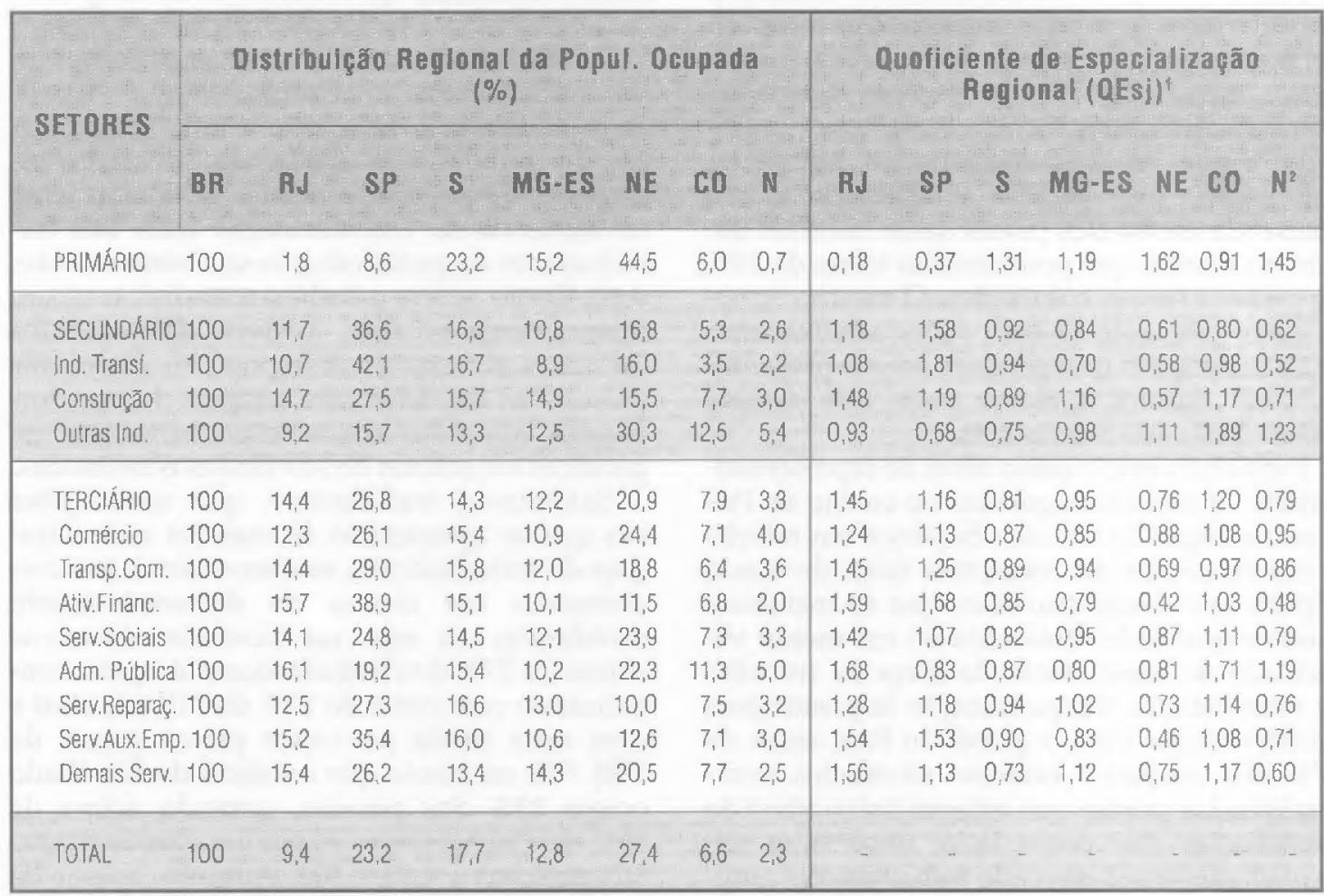

Fonte: FIBGE - PNAD/1983, Tabulação Especial.

1. QEsj = Xsj/Xj, sendo Xsj o número de populaçāo ocupada no setor s na regiāo j, e Xj o número de populaçāo ocupada na região j.

2. Inclui zona rural.

rada à do Nordeste, enquanto que Minas Gerais e Espírito Santo revelam índices superiores à unidade também na indústria de Construção e em Serviços de Reparaçāo.

Apesar de o Nordeste concentrar próximo a $17 \%$ dos trabalhadores das indústrias do País (percentual superior ao das demais regiōes), seu índice de especialização nesta área é inferior e sua "vocação" situa-se no setor Primário, que aloca quase $45 \%$ dos trabalhadores agrícolas nacionais, e apenas na indústria Extrativa Mineral o QEsj é superior à unidade. Também o Norte revela especialização nestes setores, e na Administração Pública, embora se observe forte concentração de atividades industriais de Transformação em Manaus.

\section{AS DISPERSÕES NA DISTRIBUIÇĀO OCUPACIONAL REGIONALIZADA}

Se a composiçāo das estruturas produtivas espaciais do país refletem os niveis de desenvolvimento econômico, sua distribuição ocupacional regionalizada (ver tabela 3 ) revela o grau de progresso tecnológico em cada espaço.

Para o global nacional, quase $3 / 4$ dos ocupados alocam-se em empresas (considerando-se nesse contexto desde grandes firmas monopolistas até unidades empresariais familiares) e os demais trabalham como produtores autônomos ou prestando serviços domésticos. Espacialmente o estado de São Paulo apresenta a maior representatividade nas empresas, enquanto que o Nordeste apresenta a maior participação de trabalhadores por conta própria. Observa-se, também, que para as regiões mais avançadas (São Paulo e Rio de Janeiro) os ocupados dedicados a atividades administrativas e a ocupações de Dirigentes (proprietários, administradores, gerentes), sāo relativamente mais representativos, refletindo organizaçōes empresariais mais modernas, como vimos. No CentroOeste, essas categorias ocupacionais são consideráveis, como resultado da condição de centro de tomada de decisões governamentais.

No Sudeste como um todo, apesar da condição de centro econômico polarizador, a estruturação do estado de São Paulo retrata a coexistência de tecnologias de ponta com tecnologias mais "tradicionais", que proporcionalmente se utilizam de maior representatividade de trabalhadores semiqualificados (particularmente sem atribuições de chefia), enquanto no Rio de Janeiro a participação de 
qualificados é mais elevada (principalmente com nivel superior de escolaridade) e representa um resquício da antiga condição de $\mathrm{Ca}$ pital do País, já que, em grande parte, se referem à Administraçāo Pública.

No entanto, se em São Paulo a participação de semiqualificados se situa próxima às regiōes do Sul e de Minas Gerais e Espírito Santo, a representatividade de qualificados na distribuição ocupacional paulista é superior. Estas duas regiôes de nivel intermediário de desenvolvimento apresentam as mais significativas concentrações de ocupados do país na categoria de semiqualificados sem atribuições de chefia da produção direta de bens e serviços, particularmente alocados na Agricultura e em indústrias ditas tradicionais, que apresentam menor grau de progresso tecnológico.

A estruturação ocupacional do Nordeste revela um padräo típico de processos produtivos consideravelmente menos avançados, uma vez que a participação de dirigentes e de trabalha- dores em ocupaçōes administrativas e qualificadas é a mais baixa do país, e como contrapartida a representatividade de não-qualificados na produção direta de bens e serviços é considerável ( $14 \%$, enquanto que as demais regiōes se situam entre $2 \%$ a menos de $4 \%$ ).

As regiōes intermediárias ou inferiores em nível de desenvolvimento, além do mais, retratam um potencial considerável de trabalhadores dedicados a atividades semiqualificadas autônomas, que aí se alocam por não encontrarem condições de absorção em empresas.

A observação dos níveis regionais de escolaridade, por sua vez, revela que para cada categoria ocupacional, o Nordeste apresenta uma média de anos de estudo inferior à dos demais espaços, enquanto Rio de Janeiro e São Paulo mostram uma média superior. Essas condições permitem, inferir-se a relação entre qualificação dos recursos humanos e desenvolvimento tecnológico. ${ }^{\text {? }}$

Conclui-se que as diferenças regionais na dis-

Tabela 3: Distribuição da população ocupada por categoria ocupacional, segundo as regiões (\%)

\begin{tabular}{|c|c|c|c|c|c|c|c|c|}
\hline Categorias & BRASIL & RI & SP & $s$ & MG-ES & NE & $\mathrm{CO}$ & $\mathrm{N}^{*}$ \\
\hline $\begin{array}{l}\text { EMPRESAS } \\
\text { Dirigentes }\end{array}$ & $\begin{array}{r}73,6 \\
5,1 \\
\end{array}$ & $\begin{array}{r}74,1 \\
6,4 \\
\end{array}$ & $\begin{array}{r}79,3 \\
6,7 \\
\end{array}$ & $\begin{array}{r}73,3 \\
4,8\end{array}$ & $\begin{array}{r}72,6 \\
5,6 \\
\end{array}$ & $\begin{array}{r}70,5 \\
2,9\end{array}$ & $\begin{array}{r}69,1 \\
6,4\end{array}$ & $\begin{array}{r}71,4 \\
5,0\end{array}$ \\
\hline $\begin{array}{l}\text { Produção } \\
\text { Qualific.1' } \\
\text { Qualilic. } 2^{*} \\
\text { Semi-qual. } 1^{3} \\
\text { Semi-qual. } 2^{4} \\
\text { Nẫo-qualif. }\end{array}$ & $\begin{array}{r}54,5 \\
1,9 \\
3,4 \\
39,8 \\
3,8 \\
5,6\end{array}$ & $\begin{array}{r}45,5 \\
2,4 \\
5,0 \\
30,7 \\
4,7 \\
2,7\end{array}$ & $\begin{array}{r}53,8 \\
2,8 \\
3,2 \\
39,9 \\
5,2 \\
2,7\end{array}$ & $\begin{array}{r}56,7 \\
1,5 \\
3,0 \\
46,6 \\
3,6 \\
2,0\end{array}$ & $\begin{array}{r}56,3 \\
1,6 \\
3,4 \\
45,5 \\
3,4 \\
2,4\end{array}$ & $\begin{array}{r}58,3 \\
1,2 \\
3,1 \\
37,4 \\
2,6 \\
14,0\end{array}$ & $\begin{array}{r}47,2 \\
1,9 \\
3,5 \\
35,7 \\
3,8 \\
2,3\end{array}$ & $\begin{array}{r}46,3 \\
2,6 \\
4,7 \\
30,3 \\
5,2 \\
3,5\end{array}$ \\
\hline $\begin{array}{l}\text { Administração } \\
\text { Qualific. } 1^{1} \\
\text { Qualific. } 2^{2} \\
\text { Semi-qual. } 1^{3} \\
\text { Semi-qual. } 2^{4}\end{array}$ & $\begin{array}{r}14,0 \\
1,1 \\
0,6 \\
6,9 \\
1,3\end{array}$ & $\begin{array}{r}22,2 \\
1,8 \\
1,2 \\
10,8 \\
2,3\end{array}$ & $\begin{array}{r}18,8 \\
1,6 \\
0,7 \\
9,8 \\
1,4\end{array}$ & $\begin{array}{r}11,8 \\
1,1 \\
0,6 \\
6,1 \\
0,9\end{array}$ & $\begin{array}{r}10,7 \\
0,8 \\
0,4 \\
5,5 \\
0,8\end{array}$ & $\begin{array}{l}9,3 \\
0,7 \\
0,4 \\
4,2 \\
0,9\end{array}$ & $\begin{array}{r}15,5 \\
1,0 \\
1,0 \\
6,9 \\
2,1\end{array}$ & $\begin{array}{r}20,1 \\
1,8 \\
0,8 \\
9,1 \\
2,1\end{array}$ \\
\hline Não-qualif. & 4.1 & 6,1 & 5,3 & 3,1 & 3,2 & 3,1 & 4,5 & 6,3 \\
\hline $\begin{array}{l}\text { CONTA PRÓPRIA } \\
\text { Profis.Liberais } \\
\text { Outros }\end{array}$ & $\begin{array}{r}19,0 \\
0,4 \\
18,6\end{array}$ & $\begin{array}{r}14,7 \\
0,7 \\
14,0\end{array}$ & $\begin{array}{r}12,7 \\
0,6 \\
12,1\end{array}$ & $\begin{array}{r}21,0 \\
0,4 \\
20,6\end{array}$ & $\begin{array}{r}18,2 \\
0,5 \\
17,7\end{array}$ & $\begin{array}{r}24,3 \\
0,2 \\
24,1\end{array}$ & $\begin{array}{r}20,9 \\
0,4 \\
20,5\end{array}$ & $\begin{array}{r}21,3 \\
0,2 \\
21,1\end{array}$ \\
\hline SERV. DOMESTICO & 7,4 & 11,2 & 8,0 & 5,7 & 9,2 & 5,2 & 10,0 & 7,3 \\
\hline TOTAL & 100,0 & 100,0 & 100,0 & 100,0 & 100,0 & 100,0 & 100,0 & 100.0 \\
\hline
\end{tabular}

Fonte: FIBGE - PNAD/1983, Tabulaçăo especial.

* Zona urbana.

1. Qualificados com nível técnico de escolaridade.

2. Qualificados com nivel Superior de escolaridade.

3. Semi-cualificados sem atribuiçōes de chetia.

4. Semi-cualificados com atribuições de chefia ou de maior responsabilidade.

7. Idem, ibidem, idem, para uma análise pormenorizada. 
tribuição ocupacional brasileira refletem, por um lado, as características da demanda por trabalho (estrutura produtiva); porém, essa demanda também se molda à possibilidade da introdução da inovação tecnológica em espaços em que a força de trabalho responda com maior rapidez e eficiência aos novos requisitos advindos dos processos produtivos diferenciados.

A partir dessas constatações sobre a especialização regional e a distribuição regional do avanço tecnológico, é necessário salientarse que as discussões pelos agentes econômicos (empresas, trabalhadores e governo) sobre as novas bases para uma política industrial e de desenvolvimento tecnológico que visem a retomar o nível de modernização e diminuir as desvantagens do país no cenário internacional e doméstico - a par do objetivo de ampliação da produtividade e da competitividade, devem incorporar a idéia de que a escolha entre diferentes possibilidades tecnológicas e dos setores a serem favorecidos com uma política de pesquisa leve em conta a tecnologia apropriada para as condições brasileiras. Em primeiro lugar, atentando para as particularidades espaciais dos recursos humanos e paralelamente para a possibilidade de propiciar formas eficientes de qualificação que atuem no sentido de um rápido ajustamento da mão-de-obra às novas demandas por trabalho resultantes da inovação.

Cabe aos tomadores de decisão das empresas levarem em conta que a situação de incertezas, de ambigüidades e de defasagem tecnológica, por que passa o país, exige soluções inovadoras e flexíveis no que se refere à busca da modernização, incorporando à idéia de investimento em tecnologia de ponta ou mais modernas a visão do aproveitamento das oportunidades oferecidas por novos espaços econômicos, respeitando as condições culturais e econômicas de seus recursos humanos.

\section{CONSIDERAÇŌES FINAIS}

O exame da distribuição ocupacional brasileira, aqui empreendido, revelou que as transformações estruturais em direção à modernização, que vinham ocorrendo com a crescente industrialização a partir da década de 1950 , assumiram determinados padrões em 1980 que não se alteraram no período posterior. Isto constituiu em uma perda de posição no mercado internacional em relação a outros países (NICs) que iniciaram o seu processo de industrialização no mesmo período, com o mesmo ritmo, e que, no entanto, continuaram seu desenvolvimento no período mais recente, adaptando-se a uma nova tendência mundial que prioriza o trabalho mais qualificado e o trabalhador mais flexível.

Observa-se em âmbito internacional, que a configuração ocupacional dos países de vários níveis de desenvolvimento está relacionada às características de sua estrutura produtiva e aos níveis de desenvolvimento tecnológico, associados à qualificação da mão-de-obra. Nesse contexto, no Brasil, embora apresentando um PNB/capita e uma estrutura produtiva que o situam entre os países de Renda Média Alta, a distribuição ocupacional (como indicador da modernização tecnológica, desde que apresenta uma representatividade relativamente menor de trabalhadores nas categorias mais qualificadas e maior nas não qualificadas) e os indicadores de Educação o aproximam mais de nações de menor nível de desenvolvimento, ou de Renda Média Baixa.

Por outro lado, a observação das diferenças regionais da distribuição ocupacional brasileira revela que, também internamente ao país, as diferenças em níveis de desenvolvimento econômico associam-se também a estruturas produtivas mais ou menos especializadas em setores dinâmicos e refletem o grau de desenvolvimento tecnológico dos diversos espaços. Assim, as regiões mais desenvolvidas em termos de renda per capita apresentam uma especialização acentuada em setores industriais e terciários e uma representatividade superior de ocupados em categorias mais qualificadas e em cargos de dirigentes (administradores, gerentes, proprietários), bem como uma maior participação de trabalhadores na área administrativa em relação à área de produção direta de bens e serviços. Paralelamente, as regiões mais desenvolvidas mostram um maior percentual de trabalhadores ocupados nas empresas em relação às regiões menos desenvolvidas. Nestas, a proporção de trabalhadores ocupados por conta própria e de não-qualificados na empresa é relativamente maior.

Pesquisas sobre as causas das diferenças na distribuição ocupacional e nos níveis de especialização de determinados espaços brasileiros em setores econômicos dinâmicos mostraram que, por um lado, se salientam fatores relacionados à disponibilidade de infra-estrutura e de economias de aglomeração que através do fornecimento de serviços complementares às empresas possibilitaram a introdução de tecnologias mais avançadas. Observou-se ainda que essas regiões mais avançadas apresentam um grau de integração setorial intenso com outros setores, tanto da mesma região quanto das demais, enquanto que os espaços menos desenvolvidos carecem de integração.

Porém, por outro lado, a introdução do progresso tecnológico nos diversos espaços brasileiros foi confrontada com a natureza da 
oferta de mão-de-obra regional e com a capacidade de ajustamento desta aos requisitos de qualificação demandados por novas técnicas. ${ }^{8}$ A introdução de tecnologias mais avançadas ou de ponta localizou-se nos espaços polarizados, também por conta da capacidade de incorporação mais rápida de trabalhadores mais qualificados, difundindo-se lentamente para outros espaços, através de uma "desconcentração concentradora"."

Dessa forma, qualquer discussão sobre a busca da modernização tecnológica no Brasil deve incorporar o conhecimento das diferenças regionais na realidade brasileira e a intervenção, nesse sentido, tanto governamental quanto privada, só terá bons resultados à medida que se considerar as condições regionais específicas da oferta de trabalhadores. A idéia de modernização inclui também a exploração do potencial regional da mão-de-obra menos qualificada, adaptando no curto prazo os investimentos tecnológicos às condições específicas de sua força de trabalho, enquanto não se criarem (a longo prazo) as condições para a introdução de técnicas mais avançadas.

Existem, entre as técnicas conhecidas pela sociedade e que conduzem aos objetivos de modernização, as que maximizarão o potencial social em termos de absorção de sua força de trabalho, e, portanto, serão apropriadas às características sócio-econômicas de cada realidade regional brasileira. Dentro dessa escolha pelas empresas privadas e públicas, está inserida a idéia de integrar as regiões menos desenvolvidas à matriz nacional de relações interindustriais, e de incorporar a nação como um todo na matriz mundial de relações econômicas, e, nesse sentido, é fundamental a escolha dos setores de atividades que proporcionem esta integração.

Por parte do setor público, essa integração depende diretamente de condições favoráveis efetivamente criadas por políticas governamentais que visem ao estabelecimento de uma infra-estrutura de serviços complementares, por um lado, e, por outro, o aumento da capacitação da força de trabalho, o que se inicia pelo suprimento de condiçóes básicas de aumento da escolaridade formal. Observou-se que as populações detentoras de maior nível de escolarização formal estão mais preparadas para receber treinamento adicional no próprio emprego ou em cursos especializados, de modo a se ajustarem com maior eficiência e velocidade aos requisitos de qualificação resultantes da inovação tecnológica. As medidas governamentais nesse sentido terão a finalidade de diminuir as desvantagens locacionais que determinados espaços apresentam para as empresas por acarretarem relati- vamente menores retornos aos investimentos em modernização tecnológica.

Por sua vez, por parte das empresas privadas, a escolha tecnológica apropriada pode priorizar os retornos mais rápidos ao capital, e, nesse caso, a tecnologia de ponta e a demanda por força de trabalho mais qualificada e flexível é introduzida principalmente nas regiões providas de uma infra-estrutura de serviços complementares que representam economias de aglomeração. Por outro lado, espaços menos desenvolvidos podem potencialmente oferecer algumas vantagens relativas para a escolha da localização industrial, ligadas por exemplo ao menor custo da mão-deobra, à não existência de congestionamento ou à proximidade de matérias primas específicas. Neste caso, o desenvolvimento de inversões em regiões menos avançadas deve buscar a exploração dessas vantagens comparativas, que proporcionam também o aumento da absorção de trabalhadores - ainda que por meio de tecnologias menos avançadas paralelamente às tecnologias de ponta que buscam maior produtividade e competitividade com a finalidade da obtenção do maior escoamento da produção via ampliação da renda e do mercado interno. A atividade inovadora pela empresa privada nestes espaços deve ter como filosofia a adaptação de novas técnicas à disponibilidade relativa dos fatores de produção, à natureza do mercado potencial (representado pela demanda interna e externa à região) e aos efeitos de repercussão e dispersão da modernização.

Nesse sentido, a escolha de novos produtos ou processos de produção para consumo em massa, via estandartização dos processos de produção, em espaços menos privilegiados, pode contemplar técnicas que permitam a incorporação de trabalhadores menos qualificados. Os modelos de organização gerencial de grandes empresas, já encontrados no Brasil, baseados num processo multidivisional, ou seja, na implementação da divisão de suas operações em departamentos especializados, permitem que a empresa estabeleça cada departamento em espaços que proporcionem vantagens comparativas diferenciadas, o que muitas vezes pode propiciar a dispersão de sua produção por diferentes àreas menos urbanizadas e menos polarizadas.

A modernização tecnológica no Brasil, portanto, deve contemplar não apenas o aumento da produtividade e da competitividade via a introdução de tecnologias de ponta mais sofisticadas, mas também buscar formas de organização da produção e processos de produção próprios, baseados nas condições específicas de cada espaço diferenciado. $\square$
8. Idem, ibidem, Capitulo 8.

9. Conforme pesquisa empírica de Azzoni, descrita em Indústria e Reversão da Polarização no Brasil, IPE/USP, Série Ensaios Econômicos n $58,1986$. 